\title{
Kohomba oil induced encephalopathy: lessons in prescribing traditional medicines
}

\author{
S Sri Ranganathan ${ }^{1}$, R Fernandopulle ${ }^{1}$, BVDSP Abeywardena ${ }^{2}$, HMKN Hathlahawatta ${ }^{3}$, KR Gunatilaka ${ }^{4}$ \\ Sri Lanka Journal of Child Health, 2005; 34: 94-5
}

(Key words: Kohomba oil, encephalopathy)

\section{Introduction}

Kohomba oil is a fatty acid rich extract of the Neem (Azadirachta indica or Margosa) seeds. It is used as a traditional medicine in many countries including India, Burma, Thailand, Malaysia, Indonesia and Sri Lanka as an external application ${ }^{1}$. Rarely, it is administered orally to infants in small amounts ${ }^{1}$. Several cases of Kohomba oil encephalopathy have been reported from Malaysia and Singapore ${ }^{1,2}$. Here we report a case of encephalopathy in a child following Kohomba oil ingestion.

\section{Case report}

A 7 year old girl had been prescribed Kohomba oil orally by an Ayurvedic practitioner for a skin lesion. 30 minutes after ingestion of two teaspoons of the oil she developed vomiting, followed by drowsiness. She was admitted to Kahawatte Base Hospital and three hours later she developed status epilepticus. She was given rectal diazepam and intramuscular paraldehyde but as the fits continued she was transferred to Ratnapura General Hospital for specialised management. At Ratnapura, she was given buccal midazolam and intravenous (IV) phenobarbitione.

Convulsions stopped around 4 hours from onset but within an hour she developed respiratory arrest and was intubated and ventilated. She was extubated after 36 hours but developed hypotension, bradycardia and apnoea and was re-intubated. She also received IV dobutamine, cefuroxime, netilmicin, metronidazole and aciclovir. On third day she was successfully extubated and medications were discontinued. As there was no recurrence of symptoms she was discharged on eighth day after admission.

\footnotetext{
${ }^{1}$ Senior Lecturer, Department of Pharmacology, $F / M$ University of Colombo, ${ }^{2}$ Consultant Paediatrician, General Hospital, Ratnapura, ${ }^{3}$ Registrar, General Hospital, Ratnapura, ${ }^{4}$ Demonstrator, Department of Pharmacology, F/M University of Colombo.
}

(Received on 25 April 2005)
She was a previously healthy child with no past or family history of convulsions. Parents were confident that she had not ingested any other unknown substances except Kohomba oil. She did not have any antecedent symptoms such as fever, headache or malaise. Apart from skin lesion (eczema and healing scabies), the general, systemic and funduscopy examinations were normal. On day two she showed polymorphonuclear leucocytosis (total count $2.73 \mathrm{x}$ $10 \%$ with neutrophils 91\%), moderate metabolic acidosis $\left(\mathrm{pH} 7.16, \mathrm{pO}_{2}\right.$ 46.0. $\mathrm{pCO}_{2}$ 34.6, bicarbonate $12.3 \mathrm{meq} / \mathrm{L}$, base deficit -15.4). elevated transaminases (>109 IU/L, reference range 0-40) and normal prothrombin time (test 13, control 12 seconds). Cerebrospinal fluid examination on day two was normal. Electroencephalogram on day 8 suggested an encephalopathic or encephalitic picture which reverted to normal on day 30 .

\section{Discussion}

A clinical diagnosis of encephalopathy following Kohomba oil ingestion was made based on (i) time relationship between the ingestion and clinical manifestations, (ii) absence of alternative explanations and (iii) evidence of similar cases reported in the literature.

Cases of Kohomba oil encephalopathy reported from Malaysia and Singapore ${ }^{1,2}$ too had a similar sequence of events and biochemical changes. The dose of Kohomba oil ingested by these patients varied from $5-30 \mathrm{ml}$ and the latent period between ingestion and onset of symptoms varied from 30 minutes to $41 / 2$ hours $^{2}$.

Encephalopathy following Kohomba oil ingestion could be either an adverse reaction to the therapeutic dose or a toxic effect due to over dosage. Therapeutic dose of Kohomba oil is required to differentiate these two possibilities and this information is not available in the literature.

Studies on animal models have demonstrated both toxicity to the nervous system and pronounced fatty 
infiltration of the liver and proximal renal tubules with mitochondrial damage and cerebral oedema, occurring within 3 hours of administration of Kohomba oil, compatible with Reye syndrome ${ }^{2,3,4}$. The authors suggest that Kohomba oil causes changes in fatty acid metabolism which in turn interferes with mitochondrial respiration ${ }^{4}$. Onset of hepatic toxicity is quick as the oil reaches hepatocytes within 30 minutes of ingestion ${ }^{3}$. Similar pathological findings were seen in a child who died of Kohomba oil ingestion $^{2}$.

The most likely diagnosis in our child is neem oil induced Reye syndrome, although the respiratory arrest could be either due to status epilepticus and its treatment or secondary to hepatic encephalopathy. Hypotension and consequent oliguria is most likely due to Kohomba oil, as studies in rats have shown that Kohomba leaf extracts caused bradycardia, cardiac arrhythmia and significant, dose related hypotension which are immediate, sharp and persistent ${ }^{5}$.

Management of Kohomba oil encephalopathy is mainly supportive and control of convulsions. In most reported cases prognosis was good, although occasional fatalities and neurological deficits were reported $^{1}$. Our child too recovered completely without sequelae in 72 hours.

\section{Conclusion}

Kohomba oil is a common ayurvedic medicine used in Sri Lanka. Health professionals should be aware of the adverse and toxic effects of Kohomba oil ingestion and its proper management. Genera! public should also be educated that complementary and alternative medicines are not free of risk and to seek medical advice if they notice any new symptoms following their use.

\section{References}

1. Lai S M, Lim K W, Cheng H K. Margosa on poisoning as a cause of toxic encephaiopathv. Singapore Medical Journal 1990; 31(5):463-5.

2. Sinniah D, Baskaran G. Margosa oil poisoning as a cause of Reye's syndrome. Lancet 1981: I (8218):487-9.

3. Animal model of margosa oil ingestion with Reye-like syndrome. Pathogenesis of microvascular fatty liver. Journal of Pathology 1989;159(3):255-64.

4. Koga Y, Yoshida I, Kimura A, Yoshmo M, et al. Inhibition of mitochondrial functions by margosa oil: possible implications in pathogenesis of Reye's syndrome. Paediatric Research 1987; 22:184-7.

5. Koley K M, Lal J. Pharmacological effects of Azadirachta indica (neem) leaf extract on the ECG and blood pressure of rat. Indian Journal of Physiology and Pharmacology 1994; 38(3):2235. 